\title{
Surgical management of adolescent and young adults with gastrointestinal stromal tumors: it is of value?
}

\author{
Francis Esposito, Joan Maurel \\ Medical Oncology Service, Hospital Clínic Barcelona, Barcelona 08036, Spain \\ Correspondence to: Joan Maurel, MD, PhD. Medical Oncology Service, Hospital Clínic Barcelona, Villaroel 170, Barcelona 08036, Spain. \\ Email: jmaurel@clinic.cat. \\ Provenance: This is a Guest Editorial commissioned by Editor-in-Chief Jia-Fu Ji, MD, FACS (Peking University School of Oncology \& Beijing \\ Cancer Hospital, Department of Gastrointestinal Surgery, Beijing, China). \\ Comment on: Fero KE, Coe TM, Fanta PT, et al. Surgical Management of Adolescents and Young Adults With Gastrointestinal Stromal Tumors: A \\ US Population-Based Analysis. JAMA Surg 2017;152:443-51.
}

Received: 06 October 2017; Accepted: 23 October 2017; Published: 07 November 2017.

doi: $10.21037 /$ tgh.2017.10.05

View this article at: http://dx.doi.org/10.21037/tgh.2017.10.05

Gastrointestinal stromal tumors (GIST) are the most common sarcomas of the gastrointestinal tract and are characterized by constitutive activation of the KIT or PDGFRA receptor tyrosine kinase $(1,2)$. According the Surveillance, Epidemiology and End Results (SEER) database, the incidence of GIST was 0.32 per 100,000 persons in the United States. The median age was 62 years and primary tumors are located mainly in the stomach $(58.7 \%)$ and small bowel $(31.2 \%)$. Up-front surgery is still standard therapy for located GIST (except for located GIST tumors of $<2 \mathrm{~cm}$ diameter in which observation is an option), while imatinib (a c-KIT tyrosine-kinase inhibitor), is currently used in unresectable or metastatic GIST. Despite that $50 \%$ of patients respond to Imatinib therapy, the vast majority of patients develop secondary resistance, with a median time of 2 years (3-5). In metastatic GIST without imatinib progression (either generalized or local progression), several studies suggest that surgical rescue would improve overall survival (6-13). Unfortunately, also in this favourable subset of patients, the value of surgical rescue is on debate, because the lack of a control group (patients treated with imatinib therapy with response and not treated with surgical rescue) to adequately contextualize the clinical benefit.

Fero et al., analyzed in this issue, GIST adolescent and young adults (AYA) patients (defined as those under 40 year) from the SEER database from 1998 through 2011. In this retrospective cohort study 392 AYA patients were analysed, for a total of 5,765 GIST patients (6.8\%). From this large cohort of AYA patients, 91 patients were diagnosed with

(c) Translational Gastroenterology and Hepatology. All rights reserved. metastatic disease and $55(60 \%)$ were operated. Patients who were surgically managed, have a 5 -year OS of $71.5 \%$ vs. $56.7 \%$ for patients treated without surgery $(\mathrm{P}=0.03)$. Therefore, the study suggests a substantial benefit for surgery in metastatic AYA GIST patients (14).

A prospective randomized clinical trial (NCT00956072) was designed to evaluate the potential benefit of surgical rescue in patients without progressive disease to imatinib. The study unfortunately was prematurely closed, due poor accrual. An alternative way to answer this important question is to analyze retrospective or prospective cohorts of patients with a case-control comparison. The Spanish Group for Research on Sarcoma (GEIS) evaluated 171 patients, non-refractory to imatinib, in two groups. One group (A) was treated only with imatinib (84\%) and the other (B) was treated also with surgical rescue (16\%). Median survival was 59.9 months in group A compared to 87.6 months in group B ( $\mathrm{P}=0.02)(15)$. Park et al. evaluated also a cohort of 134 patients, treated with imatinib plus surgery $(n=42 ; 31 \%)$ and with imatinib alone ( $\mathrm{n}=92 ; 69 \%)$. Overall survival was significantly longer in the surgical group (median OS; NR vs. 88.8 months; $\mathrm{P}=0.001$ ) (16).

To minimize intrinsic bias, propensity score and inverse probability of treatment weighting, can be applied for analysis. However, to adjust potential bias with this methodology, all the variables that potentially can influence progression-free survival or overall survival should be optimally recorded. In the study of Fero et al., unfortunately the most important clinical (albumin levels, disease free- 
interval, ECOG performance status, type of location, number of metastatic sites), and biological variables (type of KIT and PDGFR mutations) are missed. In addition, the study lacks all clinical information regarding imatinib efficacy in both groups of patients. Therefore, we could not firmly conclude that in metastatic AYA group of patients, surgical rescue after imatinib therapy would be indicated.

In conclusion the question of the clinical value of surgical rescue in patients with advanced GIST without progressive disease after imatinib therapy (either in AYA and older adult), is still controversial. Only a worldwide large prospective registry with all clinical variables and analyzed, with optimal methods to minimize intrinsic bias, will give a light in the dark.

\section{Acknowledgements}

None.

\section{Footnote}

Conflicts of Interest: The authors have no conflicts of interest to declare.

\section{References}

1. Hirota S, Isozaki K, Moriyama Y, et al. Gain-of-function mutations of c-kit in human gastrointestinal stromal tumors. Science 1998;279:577-80.

2. Heinrich MC, Corless CL, Duensing A, et al. PDGFRA activating mutations in gastrointestinal stromal tumors. Science 2003;299:708-10.

3. Blanke CD, Rankin C, Demetri GD, et al. Phase III randomized, intergroup trial assessing imatinib mesylate at two dose levels in patients with unresectable or metastatic gastrointestinal stromal tumors expressing the kit receptor tyrosine kinase: S0033. J Clin Oncol 2008;26:626-32.

4. Blay JY, Le Cesne A, Ray-Coquard I, et al. Prospective multicentric randomized phase III study of imatinib in patients with advanced gastrointestinal stromal tumors comparing interruption versus continuation of treatment beyond 1 year: the French Sarcoma Group. J Clin Oncol 2007;25:1107-13.

5. Van Glabbeke M, Verweij J, Casali PG, et al. Initial and late resistance to imatinib in advanced gastrointestinal stromal tumors are predicted by different prognostic factors: a European Organisation for Research and Treatment of Cancer-Italian Sarcoma Group-Australasian Gastrointestinal Trials Group study. J Clin Oncol 2005;23:5795-804.

6. Gronchi A, Fiore M, Miselli F, et al. Surgery of residual disease following molecular-targeted therapy with imatinib mesylate in advanced/metastatic GIST. Ann Surg 2007;245:341-6.

7. DeMatteo RP, Maki RG, Singer S, et al. Results of tyrosine kinase inhibitor therapy followed by surgical resection for metastatic gastrointestinal stromal tumor. Ann Surg 2007;245:347-52.

8. Bauer S, Hartmann JT, de Wit M, et al. Resection of residual disease in patients with metastatic gastrointestinal stromal tumors responding to treatment with imatinib. Int J Cancer 2005;117:316-25.

9. Andtbacka RH, Ng CS, Scaife CL, et al. Surgical resection of gastrointestinal stromal tumors after treatment with imatinib. Ann Surg Oncol 2007;14:14-24.

10. Bonvalot $\mathrm{S}$, Eldweny $\mathrm{H}$, Péchoux $\mathrm{CL}$, et al. Impact of surgery on advanced gastrointestinal stromal tumors (GIST) in the imatinib era. Ann Surg Oncol 2006;13:1596-603.

11. Raut CP, Posner M, Desai J, et al. Surgical management of advanced gastrointestinal stromal tumors after treatment with targeted systemic therapy using kinase inhibitors. J Clin Oncol 2006;24:2325-31.

12. Mussi C, Ronellenfitsch U, Jakob J, et al. Post-imatinib surgery in advanced/metastatic GIST: is it worthwhile in all patients? Ann Oncol 2010;21:403-8.

13. Bauer S, Rutkowski P, Hohenberger P, et al. Longterm follow-up of patients with GIST undergoing metastasectomy in the era of imatinib -- analysis of prognostic factors (EORTC-STBSG collaborative study). Eur J Surg Oncol 2014;40:412-9.

14. Fero KE, Coe TM, Fanta PT, et al. Surgical Management of Adolescents and Young Adults With Gastrointestinal Stromal Tumors: A US Population-Based Analysis. JAMA Surg 2017;152:443-51.

15. Rubió-Casadevall J, Martinez-Trufero J, Garcia-Albeniz X, et al. Role of surgery in patients with recurrent, metastatic, or unresectable locally advanced gastrointestinal stromal tumors sensitive to imatinib: a retrospective analysis of the Spanish Group for Research on Sarcoma (GEIS). Ann Surg Oncol 2015;22:2948-57.

16. Park SJ, Ryu MH, Ryoo BY, et al. The role of surgical resection following imatinib treatment in patients with recurrent or metastatic gastrointestinal stromal tumors: results of propensity score analyses. Ann Surg Oncol 2014;21:4211-7.

doi: $10.21037 / \operatorname{tgh} .2017 .10 .05$

Cite this article as: Esposito F, Maurel J. Surgical management of adolescent and young adults with gastrointestinal stromal tumors: it is of value? Transl Gastroenterol Hepatol 2017;2:86. 